\title{
PAPELES PROHIBIDOS DEL FASCISMO EN ESPAÑA
}

\author{
Crujian los papeles prohibidos \\ J. M. Caballero Bonald, "El registro", \\ Pliegos de cordel, 1963
}

Habrá que decirlo una vez más. La situación está controlada. Hoy, a punto de legalizarnos el estado socialdemócrata su operación Memoria Histórica, a nadie le cabe duda alguna: el alto coste a cargo de los presupuestos públicos imposibilitará de hecho desenterrar los cadáveres, saber quiénes y cuántos o hasta qué punto aguantaremos nuestros vómitos ante el tamaño infinito del genocidio o volumen insondable de la masacre ejecutada por el fascismo en los años de la contrarrevolución y de la guerra de clases (1936/1939) y, tras su victoria, desde los Años Triunfales o años cuarenta hasta su socialización o natural transición -política, social, económica e ideológica-, la supuesta o falsa transición de la dictadura a la democracia, al fascismo democrático, hasta hoy'.

No se revisarán ni siquiera los crímenes de estado oficiales, aquellas sentencias de los Tribunales Militares cuya jurisdicción perdurará desde los primeros meses de la guerra hasta entrecruzarse con el TOP (o Tribunal de Orden Público) ${ }^{2}$. No sabremos nunca nada sobre las operaciones de limpieza y sus órdenes ejecutivas no sólo por parte de la autoridad militar de campo, sino por parte de las autoridades políticas o ya gubernamentales, convertida ya toda España en una inmensa retaguardia, en un campo de concentración o en una cárcel inmensas ${ }^{3}$. Nada que saber de la composición voluntaria de los pelotones de ejecución, ni de los denunciantes no menos voluntarios, de las acusaciones particulares y persecución de rojos y sus delitos retroactivos en una Causa General permanente abierta, ni del reparto del botín de guerra ni de las peleas internas entre los vencedores por acapararse las prebendas que otorga el Nuevo Estado, el nuevo orden en los poderes políticos, sociales o eclesiásticos, municipales o en las diputaciones provinciales, en organismos e instituciones profesionales, culturales, universitarias, etc. ${ }^{4}$ Nada que saber de los jefes y jerarcas de Falange e incluso de sus afiliados, tampoco de los dirigentes contrarrevolucionarios, delegados del gobierno y del Movimiento, ministros o subsecretarios, directores generales o directores de periódicos, policías, alcaldes o censores, obispos o la última jerarquía de la Iglesia o de Falange Española Tradicionalista y de las JONS (Juntas Ofensivas Nacional Sindicalistas), etc. ${ }^{5}$

Nada que saber de los representantes, gestores y agentes ideológicos de la contrarrevolución y el fascismo; de quienes personificaron y ejercieron las funciones funda-

\footnotetext{
1 Cf. Aguilar, 1996; Casanova, 2002; Espinosa, 2003; Brendel y Simon, 2004; Malefakis, 2006: 16-17.

2 Cf. VV. AA., 1990; Águila, 1991; Domínguez, 2004; Espinosa, 2005.

3 Cf. Colectivo 36, 1976; Moreno, 2001; Vinyes, 2002; Hernández, 2003; Acosta et alii,, 2004.

4 Cf. Eiroa, 1995; Cenarro, 1997; Martín, 2002; Palomares, 2002.

5 Cf. Jerez, 1982; Chueca, 1983; Parejo, 2004; Iglesias, 2007: 54.
} 
mentales de legalización y legitimación de los crímenes, del genocidio político social de clase ejecutado desde aquel verano del 36 al largo año del 75 y cuyos cadáveres tampoco reconoceremos. Nada que saber del cuerpo de funcionarios jurídicos, encargado de levantar un nuevo estado de derecho allí donde no había sino facciosos y asesinos, criminales lúcidos, conmilitones africanos de razzias y matanzas, horda de bárbaros para nada patológicos sino conscientes del trabajo sucio que los dueños de los medios de producción o burguesía de terratenientes y capitalistas le exigían frente a la amenaza de una inviable revolución proletaria y campesina en España ${ }^{6}$. Y aun más, nada que saber de sus compañeros funcionarios del intelectualismo orgánico contrarrevolucionario y fascista, los ideólogos e intelectuales, los maestros nacionales y profesores universitarios, los escritores, los novelistas y dramaturgos, los periodistas, los poetas. ${ }^{7}$

Así, nada que saber del funcionariado jurídico contrarrevolucionario y fascista; jueces y abogados, del aparato legislativo de represión y castigo, del cuerpo de leyes del terrorismo de estado. Pero, qué decir cuando "nunca las columnas de la Gaceta o el Boletín Oficial [del Estado] han hablado a los españoles con tan solemne y habitual dignidad", como cuando redactaban si no las leyes sí sus preámbulos -perfectos panfletos de legitimación y gloria, de exaltación y triunfo del fascismo y contrarrevolucionarismo-los D'Ors, los Pemán, etc. ${ }^{8}$ Qué decir cuando la propaganda resultaba fundamental para la causa de las armas facciosas, para asesinar también ideológicamente, para el control y encuadramiento ideológico, para la ideologización de "España y los españoles". Qué decir cuando una consigna clave, un dogma de combate fija toda la política cultural e ideológica fascista desde su proclamación y en todas las fases de su proceso de formación, ascensión e imposición, que "a los pueblos no los ha movido nunca más que los poetas, y jay del que no sepa levantar, frente a la poesía que destruye, la poesía que promete!"10.

Nada que saber, pues, del poeta conductor o caudillo de los pueblos. Nada que saber, ni en la teoría -escasa- ni en la práctica -abundante-, en los papeles que el funcionariado ideológico de clase -los FICs-y de estado produce, escribe y hace público por el aparato de P. P. y $P$, esto es, Prensa y Propaganda y Publicaciones. Nada que saber del poeta o escritor -esto es, el intelectual orgánico- jefe o jerarca o camarada. Que sirve o milita "como escritor falangista, con jerarquía de gobierno"11 o encuadrado en las fillas del bloque de fuerzas coaligadas contrarrevolucionarias victoriosas en la guerra de clases de 1936/39, en los lugares que corresponda al servicio, ya lugares de dirección -esto es, lugares ocupados por el fascismo y sus funcionarios-o ya lugares subalternos -igual fascistas que contrarrevolucionarios- en las entrecruzadas e interconflictivas jerarquías del funcionariado en los aparatos del Estado o del Movimiento, de la Falange.

Nada que saber de escritores e ideólogos o intelectuales orgánicos, o de simples funcionarios ideológicos, jefes o jerarcas o camaradas. ¿Por qué?

6 Cf. Morodo, 1985; Rivaya, 1998; Malefakis, 2001.

7 Cf. Pérez y A. Fuentes, 1986; Andrés Gallego, 1997; Morente, 1997; Claret, 2006.

8 Cf. Aranguren, 1945 (y no la edición revisada por el propio autor, con prólogo de J. L. Abellán, Madrid: Austral, 1981).

9 Cf. Reig Tapia, 1986; 1990; 2006. Cf. también Vilanova, 2005.

10 Cf. Primo de Rivera, 1954.

11 Cf. Ridruejo, 1940: 93-100. 
Hay tres tendencias de razones que explican este vacío, este silencio, este olvido, este pacto o transacción firmado en los años de la falsa o natural transición de la dictadura a la democracia y al fin al fascismo democrático a día de hoy, cuando el hueco este adquiere ya proporciones de agujero negro, por donde se pierde todo conocimiento y donde se abre una desmemoria tan voraz que no sólo borra sino que además falsifica, tergiversa, engaña, estafa, levanta las banderas de nuestros adorables héroes laureados allí donde sólo encontramos miserables legitimadores del terrorismo de clase y de estado.

La primera razón se sitúa a la par de las dificultades con que trabajan las investigaciones históricas. Los historiadores tienen complicado el acceso a los archivos, a las fuentes primeras de información y documentación ${ }^{12}$. Y así también nosotros. Por centrarme en un caso concreto que a partir de aquí voy a tomar como referente obligado, para no quedarme en generalidades ni en cómplices aporías; sino en un caso notorio y socializado, con premios y prestigios alcanzados hasta el máximo que les otorgan los poderes de clase a sus más fieles, eficientes y eficaces servidores; el caso de nuestro intelectual orgánico del fascismo, poeta, escritor y novelista Camilo José Cela. Así que, respecto de este caso y entre otros hechos: primero, en el Archivo General de la Administración no está, ha desaparecido su expediente de funcionario; segundo, si buscamos en el cúmulo de infundios ${ }^{13}$ que se intitula Memorias, entendimientos y voluntades ${ }^{14}$ y pretendemos averiguar algo sobre la "chapa de identificación militar" de Cela, nos encontraremos con que precisamente remite a regimientos y batallones en los que se han perdido sus archivos por completo, y, si no abandonamos la página en la que aparece fotografiada la chapa, imposible resultará contrastar la autenticidad de la firma de Indalecio Prieto como ministro de Defensa Nacional autorizándole a Cela nada más y nada menos "para marchar al extranjero"; aunque más fácil resulta descubrir el montaje en el "grupo de soldados de artillería" fotografiado precisamente "en lo que hoy se llama Paseo de Camilo José Cela", que se publicita en la página de fotografías de al lado, incorporando sombras estratégicas junto a una nitidez insólita para esas fotos de época, unos personajes de uniformes abigarrados e imposibles en "el ejército nacional", un tal "teniente Ordax" que vaya usted a saber de su existencia en los archivos militares o averiguar el sastre que lo viste no sé para qué ocasión o carnaval, que no para "nuestra guerra", ni aun menos acompañado de ¿su? "perro Wolf", cuando por si aun faltara algo se parece mucho/muchísimo al general Franco de los años 50. Y a todo esto, los datos e informaciones colaterales e indirectas que nos llegan inequívocamente señalan y ubican al soldado Cela en la legión, para nada o nunca en Madrid -donde fantasea aventuras sin cuento ni relación alguna con la situación interna ciudadana, ni con la quintacolumna falangista, etc., aunque sí con Prieto de "ministro" y otras tantas afinidades republicanas o amistades varias de familia, por supuesto- sino "prófugo en 1936, soldado nacional en 1937", en la retaguardia de Galicia, en el frente de Extremadura, "cabo del Regimiento de Artillería número 16" o "legionario", siempre a las órdenes de "mi general" Millán Astray, etc. ${ }^{15}$

12 Cf. notas precedentes. Tambiên Viñas, 2006; 2007. Cf. Bolloten, 2005; pero, cf. Southworth, 1999: 265-310. Cf. Southworth, $1963 ; 1967$.

13 Cf. García Serrano, 1947.

14 Cela, 1993.

15 Cf. Figueres, 2004; Cervera, 2006. Cf. Z[unzunegui], enero 1943; C[astro] V[illacañas], febrero 1943; Giménez Caballero, abril 1943: 3-4; Aparicio, 1945; Umbral, 1993; Rodríguez Rivero, 28 noviembre 1998: 3. 
La segunda razón se completa con esta primera, para que no quede ni rastro documental ninguno del pasado de militancias y servicios de nuestros FICs fascistas y contrarrevolucionarios. Se trata del oneroso capítulo de sus inventos y mixtificaciones, de sus memorias y descargos de conciencia, que les lleva a situarse en lugares mucho más aun que indocumentables, esto es, falsos o falsificados. No hablo ahora de los casos por excelencia de Ridruejo o Laín Entralgo -de los que se habría de ocupar la tercera razón-; hablo de Cela en concreto y como digo, porque sus palabras han quedado aceptadas e incuestionables, configurando la versión oficial establecida de la historia de la novela y desde ahí toda la literatura de postguerra. Entre otros hechos, las presuntas censuras sufridas por La colmena y La familia de Pascual Duarte. ¿Que nadie se ha molestado en ir al Archivo General de la Administración? Ah, no importa. Nos valen los artilugios montados: que si irse a Emecé y la Argentina fascista de Perón, por empecinarse en no aceptar

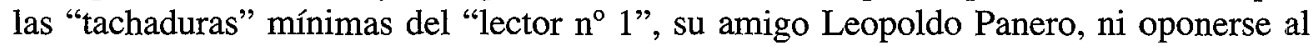
lógico informe negativo del lector eclesiástico -el padre Andrés de Luna, también lector, eclesiástico pues, de La familia de Pascual Duarte, sin que censurase ahí nada-. Años de empecinamientos y no de huidas de la censura, los años 1946/51/53, cuando sus camaradas, altos jerarcas de Falange todavía en la Vicesecretaría de Educación Popular, Delegación Nacional de Propaganda / Subsecretaría de Educación Popular, Dirección General de Propaganda, no ocupan los puestos ejecutivos, tomados ahora por jóvenes Propagandistas y mandos de Acción Católica ${ }^{16}$; precisamente, donde coloca a sus Directores Generales de Prensa y de Propaganda que en dos tarjetas privadas -ninguna oficial; ninguna con sello ni registro de salida- se dedican a lamentarse del sexo de los ángeles: se cartean, pese a estar sus respectivos despachos pared con pared en el mismo edificio, "Monte Esquinza, 2, esquina a Génova"; no leen los ejemplares de censura, sino volúmenes personales que mutuamente "tengo a tu disposición" y que se compran no al precio de 1945/46, a "veinte pesetas", sino a "cuarenta pesetas", precio de los finales años cincuenta; se citan mal y torpemente la referencia de "la calificación moral" de Ecclesia (Órgano de la Dirección Central de la Acción Católica Española) emitida en marzo de 1944, esto es, hacía ya más de dos años y como si estuviese de actualidad; en una entrega doble -sintomáticamente una garabateada, más que firmada, y la otra ni siquiera eso- hecha pública ¡a fecha de 1989! nada menos, cuando Cela decide al fin ¡"revelar la censura"! de La familia $a^{17}$; etc.

La tercera razón complementa y supera las dos primeras razones, en tanto que no se pierde en la mera destrucción de pruebas o documentos ni en la burda falsificación de papeles; sino que directamente los pone a recaudo y fuera de la circulación intelectual, fuera del trabajo de investigación y crítica de la literatura, fuera del pensamiento literario. Directamente los prohíbe, o aun más, los clasifica o cataloga como papeles prohibidos; por supuesto, sin que se note su artimaña, su clasificación o catalogación, su prohibición.

Esta tercera razón la elaboran, la organizan, la publicitan e imponen al fin una serie de funcionarios ideológicos situados preferentemente en las altas jerarquías administrativas docentes del aparato universitario; esto es, el funcionariado ideológico de clase y de estado -los FICs- en el ejercicio de sus funciones fundamentalistas en primer lugar del

16 Cf. Montero, 1993.

17 Cf. Cela, 2 junio 1989: 1 y 16; Zamora Vicente y J. Cueto, 1995. Cf. Bedoya, 4 marzo 1982. 
intelectualismo orgánico del fascismo, y en último lugar o lugares del propio fascismo y su dominio de clase en la historia. Servicio fundamentalista pues que hacen con diversas fórmulas; entre las más reproducidas, socializadas o aun vulgarizadas están: el absurdo falangismo liberal del intelectualismo fascista de estado o "en la alta manera" -dicho con su ideólogo, el intelectual fascista don Pedro Laín Entralgo, noviembre de 1940- o "con jerarquía de gobierno" -dicho ahora con el intelectual fascista Dionisio Ridruejo, noviembre 1940-; la gruesa resistencia silenciosa o exilio interior al dominio -no sólo ideológico- de clase del fascismo en España; la exaltación y gloria de "nuestros adorables reaccionarios" o "héroes" o "virtuosos de la integridad", nuestros fascistas ${ }^{18}$.

Una "solución final" para el fascismo o "ley de punto final" para los fascistas. Un asalto a la razón y a la historia, que hoy se propala con todo el aparato de los poderes de clase (económicos, sociales, políticos, ideológicos e intelectuales) en un mercado ávido y consumista de un pensamiento único, postmoderno o reaccionario, cuando no abiertamente fascista o neofascista, como ideología de uso y consumo para el régimen de fascismo democrático bajo el que vivimos ${ }^{19}$. Contra el que sólo cabe la desclasificación de papeles prohibidos.

Tengamos el caso de Cela. ¿Qué hacer? De una parte, qué hacer para demostrar lo evidente o lo legible, lo que está escrito, lo que está por escrito o hecho público, publicado y aun hoy todavía constituye un cuerpo de textos -literarios, por supuesto; periodísticos a lo sumo- con el que se ideologiza a unos ciudadanos normales desde sus estudios de bachillerato, con lecturas regladas y obligadas de La familia de Pascual Duarte más que La colmena o cualquier otra de sus novelas. Se trata de materiales, documentos textuales puestos en circulación a las claras y a las bravas, sobre los que interviene o recae una abrumadora cantidad de interpretaciones, de lecturas establecidas, oficializadas por el prestigio que en un círculo vicioso les confieren los FICs y los propios aparatos ideológicos de clase y de estado que masivamente los producen y reproducen respectivamente sin solución de continuidad. Aquí y en primer lugar, cabría poner a disfuncionar esa cadena de transmisión y su montaje con una lectura bifurcada y entrecruzada: una lectura escritural que descubra la lógica interna del texto en sus razones, en sus contradicciones e incoherencias, en su escritura e inescritura, en lo que escribe e inescribe, en lo que alude y lo que elude, en hueco o vacío, con fuerza o incompetencia, etc.; y al tiempo una lectura histórica, dirigida hacia los lugares, situaciones, hechos, acontecimientos y coyunturas hacia las que la escritura nos conduce e induce al señalarlas expresamente. Así, entre otros asuntos, las lecturas del notario, del cura y el guardia civil, de la mano del escritor, para dar realidad y vida a Pascual Duarte, criminal y reo "convicto y confeso" del "asesinato" del "patricio don Jesús González de la Riva, Conde de Torremejía, quien al irlo a rematar", "durante los quince días de revolución que pasaron sobre su pueblo"; de la "Cárcel de Badajoz, 15 de febrero de 1937" y de la cárcel de "Mérida (Badajoz) y

$18 \mathrm{El}$ asunto comienza en la coyuntura de 1968, con las propuestas de E. Díaz y J. C. Mainer, que hoy alcanzan cotas inigualadas de prestigio y reconocimiento. Contra su mercado, cf. Rodríguez Puértolas, 2007. Por mi parte, lo investigo en un ensayo en curso, La última piel de la serpiente. Hagiografismo y apología del intelectualismo fascista en España, 1966-[...]. Cf. Fortes, enero-junio 2006: 18-19. Una última escalada apologética y hagiográfica la mercantiliza Gracia, 2007, donde al fin resulta y se publicita " "el fascismo como ruptura violenta del orden burgués"!

19 Cf. Negró, 2006: García Viñó, 2006. 
en trance de muerte, a 11 de mayo de 1937"; de las cárceles, y de las monjas y los curas en las cárceles; no del juicio, sino de la condena y de la ejecución no por fusilamiento sino a "garrote vil"; etc. ${ }^{20}$

Está pues la prohibición implícita, a veces gruesa y nada subliminal, sobre textos notorios, conocidos, leídos oficialmente por activa y por pasiva, que por contra nos obliga a cuestionar y denunciar de arriba hasta abajo toda la historia de la literatura y del intelectualismo que la produce, en estricto, como una cadena -de transmisión- de lugares y complicidades necesarias para la fundamentación del dominio de clase burgués capitalista a través del fascismo y su ideología. Así por ejemplo, téngase la sistemática exaltación de La familia de Pascual Duarte, hasta encontrarse nombrada expresamente en la concesión del Premio Nobel a Cela, los homenajes y nominaciones que recibe, el dogma de fe que la levanta "en 1942, cuando todo -hasta el honor y la novela-parecía perdido en este país", "en solitario y de repente", desde entonces "destinada a convertirse [...] en el ejemplo y el revulsivo de nuestra literatura, refugiada en el exilio o en la forzosa clandestinidad del silencio, y del desánimo, [que la] necesitaba para levantar cabeza y ponerse de nuevo en marcha"21. Sin embargo, este fundamentalismo no se basta a sí mismo en su cadena de burdas y gruesas prohibiciones implícitas, y ha de echar mano de un cuerpo absoluto y totalitario de prohibiciones explícitas.

Sin estas prohibiciones explícitas, imposible producir y reproducir la función fundamentalista del dominio -no sólo ideológico- de clase burgués capitalista, a través del fascismo y su ideología e intelectualismo orgánico. Y ello, aunque suponga sostener un continuo asalto a la razón y a la historia.

Téngase el desconocimiento impuesto -prohibitivamente, pues- en torno a los Años Triunfales o años 40 del fascismo de estado, considerados como los "años oscuros" cuando ello constituye un caso flagrante y torpe de empecinado oscurecimiento de los hechos, puestos al revés, en la negación y ocultamiento atroz, como si nunca hubieran ocurrido, "años oscurecidos"22. Contra lo que sólo cabe el descubrimiento de pruebas y documentos, poner al descubierto los papeles prohibidos del fascismo en España. Sacarlos uno a uno del olvido, del borrado histórico, de la inexistencia histórica. Para su lectura e investigación.

Por supuesto, en una tarea ingente e imposible, si la emprendemos de golpe y todos o ninguno. Por el contrario, puede que la exhaustividad resulte una trampa, en la que no hay por qué caer, sino que, una vez oído y eludido su canto de sirena, el camino se emprenda paso a paso, poco a poco, texto a texto, documento a documento, periódico o revista o libro o editorial de una a una, de uno a uno cada escritor o intelectual orgánico de nuestro adorable fascismo. Sólo, ateniéndose a la materialidad de los hechos, de los papeles o escritos publicados. Así por ejemplo y en el caso de Cela, se comenzaría por una recopilación de artículos o sueltos o cuentos o poemas o colaboraciones, etc., en las

20 Cf. Espinosa, 2006.

21 Cf. el Manifiesto con el que "un grupo de escritores destaca el valor de ruptura de la obra literaria de Cela", $E l$ País (17 julio 1983): 21; seguido del panegírico de J. Cruz, "La luz de esta memoria". Cf. Suplemento especial de El País (20 octubre 1989).

22 Cf. Martínez Cachero, 1973; que inicia una especie de saga inmutable y acumulativa entre 1936 y 1975 (1979), entre 1936 y el fin de siglo (1997), etc. 
revistas y periódicos de la prensa o cadena del Movimiento; con resultados precisos y subversivos.

Esta recopilación del trabajo y participación de Cela en los aparatos de prensa y propaganda del fascismo -por la prueba de los hechos y como asunto colectivo-, volvería obsoletas y absurdas todas y cada una de las mil coartadas con las que se premia los servicios prestados al intelectualismo y funcionariado ideológico fascista, cuyo punto de inflexión y no retorno va a alcanzarse en los pactos y transacciones de la transición política del 75/82, a cuyos nombres el publicismo de clase les reconoce el rango de ley de punto final o solución final, aunque su denominación cambie según los lugares de trabajo o servicio; en el campo de la literatura y alrededores se les denomina posibilismo sin más ${ }^{23}$ y en contadas ocasiones colaboracionismo al menos ${ }^{24}$. Esto, en primer lugar. En segundo lugar, se caen por su propio peso de uno a uno todos los subterfugios colaboracionistas, hasta descubrirse en su exacta dimensión, como una pieza más pero pieza indispensable para la producción de ideología fascista, de fascismo y su ideología ajustada a cada necesidad o cada problema, a cada utilidad o cada propuesta de construcción del Nuevo Estado y la España Nueva nacionalsindicalistas que el fascismo organiza y desde su predominancia batallará por imponer al resto de fuerzas coaligadas contrarrevolucionarias vencedoras en la guerra de clases de 1936/39.

En este segundo lugar, y para que se me entienda, no bastará con que se descubra, se publique y señale la procedencia de los cuentos recopilados en Esas nubes que pasan (1945); o que la prensa o cadena del Movimiento se vuelque en reseñar La familia de Pascual Duarte que - icon errata inicial incluida?- se publicita en El Español (6 [5 diciembre 1942]: 15), al igual que Pabellón de reposo (20 [13 marzo 1943]: 14; y ss.) o Viaje a la Alcarria como "Itinerarios españoles. Las botas de siete suelas. Camilo José Cela se hace viajero" (191 [22 junio1946]: 1, 7), y "Primera salida. La Alcarria (192 [29 junio 1946]: 16, 4), etc.; o que "las primicias", el capítulo primero de $L a$ colmena se traslade desde Emecé -esto es, sin corrección de tachaduras- a Cuadernos Hispanoamericanos (15 [mayo-junio 1950]: 535-563), al tiempo que se monte una discusión pública o literaria sobre La colmena ya leída en Índice de artes y letras (44 [15 octubre 1951]: 1, 21); etc., etc. Sino que, han de explicitarse las razones, por qué esta situación, estas relaciones, toda esta red de lugares e influencias, como no se producirá en ningún otro "adorable escritor" de los años triunfales del fascismo -del fascismo de estado- y de los años inmediatos a su derrota política en las jerarquías del gobierno.

¿Por qué? La complejidad intrincada e ignota -supuestamente- de las razones puede empezar a desvelarse o deshacerse en cuanto comencemos a leer los textos o documentos originarios. Por ejemplo: en el suplemento Sí, de Arriba -aparato directo de prensa y propaganda de Falange en sus "altas jerarquías de gobierno"-, publica Cela el panegírico "De la interpretación española de la muerte" -"demostrada sobre las tierras soviéticas" como reza el pie de foto adjunta de soldados de la División Azul-, con el subtítulo de "Reflexiones al borde de un octavo aniversario", dentro de un monográfico

$23 \mathrm{El}$ posibilismo circula sin problema alguno en la historiografía al uso, tanto en la generalista como en la especializada; aunque alcanza sus mayores cotas de propagación con las ocasiones necrológicas, en los panegíricos y hagiografías puntuales con motivo de la muerte del escritor o ideólogo o intelectual fascista o colaboracionista de turno. Ténganse las de Cela, Laín Entralgo, Torrente Ballester, García Nieto, Rosales, José Hierro, etc.

24 Cf. Martínez Cachero, julio-agosto 1978: 34-50; Martín, junio 1982: 14-18. 
-6 [8 febrero 1942]: 14- dedicado a la exaltación de "El estudiante caído", estudiante del SEU (Sindicato Español Universitario) en cuyas escuadras de combate -y por tanto de muerte callejera- militaba Cela, el escuadrista que ahora "da razón" y consignas, junto con todos los camaradas victoriosos que se reparten las prebendas de la victoria en la guerra. La segunda entrega del panegírico -"De la interpretación española de la muerte (Tres reflexiones más, sangrante aun su recuerdo"; se refiere a Matías Montero, protomártir del "estudiante caído"- la publica en Haz. Semanario de la juventud. SEU

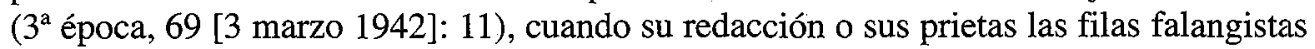
de periodistas ya se han multiplicado en Juventud. Semanario de combate del SEU (24 febrero 1942), donde trabaja o sirve Cela con jerarquía de redactor jefe, y al año en $\mathrm{Haz}$ ( $4^{\circ}$ época; febrero 1943), etc.

Así que, en tercer lugar, la situación y las relaciones adquieren ya su materialidad real e histórica, en los puestos de servicio, en estricta "jerarquía de mando y de gobierno", en los aparatos y el funcionariado ideológico del fascismo de estado en España. En Haz ( $3^{a}$ época; 9 [7 enero 1941]: 11), bajo el titular a toda la página de "Tres españoles [Luis Escobar, Tomás Borrás, Huberto Pérez de la Ossa] dedicados por completo a la dignificación de la escena española escriben para Haz", y con motivo de "la representación del 1 de enero [que] el T.E.U. [Teatro Español Universitario] de Valencia, de paso para la capital burgalesa, donde ha de intervenir en la conmemoración que esta ciudad ha hecho del VIII Centenario del Poema del Cid", montó en el Teatro Español de Mádrid, se publica la "PRESENTACIÓN que el camarada Camilo José Cela, Secretario de la Delegación Nacional de P. P. y P. para el Distrito Universitario de Madrid, hizo de 'Las mocedades del Cid', en el Teatro Español, la noche del día $1^{\circ}$ de año.

Señoras y señores, camaradas:

El Teatro Español Universitario se presenta esta noche ante vosotros con lo que tiene: una inmensa voluntad, un ansia de renovación extraordinaria y un deseo sanísimo de contribuir -en la proporción que nos sea dada- a la desintoxicación de la escena española. Cuando compañías de profesionales, con medios y con una técnica casi buena a su disposición se pierden en papirusismos pequeños burgueses, o lo que es peor, en los recovecos pedantéelos de las denominadas enfáticamente 'Obras de tesis', nosotros -los estudiantes- propugnamos y realizamos un teatro, que nos saldrá mejor o peor, pero que cuando menos - y no es poco- es sincera y honradamente llevado.

El T.E.U. Nacional -en vías de total reorganización- ha encargado a los camaradas de diversas provincias el estudio y la puesta en marcha de varias obras clásicas. Hoy ha sido a Valencia a quien ha correspondido trabaja; los estudiantes valencianos llegan a nosotros con sus Mocedades del Cid perfectamente montadas... si todavía queda un fondo de conciencia entre los gerifaltes del Teatro comercial, ¿no han de sentirse un poco avergonzados de que hayamos sido nosotros quienes, liándonos la manta a la cabeza, nos hayamos metido de lleno en el berenjenal en que nos hemos metido, por nuestra sola intención -quijotesca si queréis- de levantar a nuestro teatro de la postración en que, quien haya sido, le ha sumido?

Habríamos cumplido sobradamente nuestro propósito si, después de esta representación, uno tan sólo de los que ven en el teatro no una función social y docente a realizar, sino un negocio, pensase -desapasionadamente- durante cinco minutos en lo que hacemos o en lo que queremos hacer. Pero como no venimos, gracias a Dios, a cosechar lau- 
reles con una propensión mayor o menos a la sequía, ni a intrigar a ninguno con los misterios que en cualquier bajo de Madrid, y alrededor de la camilla, podrían suceder cada lunes y cada martes, sino que venimos a cumplir seriamente lo que nos hemos propuesto, que es llevar a la masa estudiantil la convicción de que el teatro es otra cosa, y mayor de lo que el vulgo errante, municipal y espeso -como lo hubiera clasificado Rubén- se cree, no nos consideraremos saciados mientras todos vosotros -y uno por uno- no estéis completamente acordes, no estéis totalmente sintonizados con lo que representamos.

Día llegará, no lo dudéis, en que lo que hoy es un experimento, sea una bella y agradable realidad. Hasta entonces... una única y constante actitud; el Teatro al uso no nos sirve, queremos otra cosa mejor y más de acuerdo con nuestra manera de entender la vida; proclamamos nuestra incompatibilidad con lo que se hace, y como no encontramos -entre los que lo hacen- quien pueda mejorarlo, nos irrogamos una obligación más a las muchas que ya tenemos: hacer teatro.

¡Arriba España! "25.

\section{BIBLIOGRAFÍA}

Acosta, G. et alii (2004): El canal de los presos (1940-1962). Barcelona: Crítica. Águila, J. J. del (1991): El TOP. Barcelona: Planeta.

Aguilar, P (1996): Memoria y olvido de la Guerra Civil española. Madrid: Alianza. Andrés Gallego, J. (1997): ¿Fascismo o Estado católico? Madrid: Encuentro.

Aparicio, J. (1945): Españoles con clave. Barcelona: Caralt Editor.

Aranguren, J. L. (1945): La filosofía de Eugenio D'Ors. Madrid: EPESA.

Bedoya, J. G. (4 marzo 1982): "Cartas de censores". En: El País.

Bolloten, B. (2005): Revolución y contrarrevolución. Madrid: Alianza.

Brendel, C. y H. Simon (2004): Ilusiones políticas y lucha de Clases. Bilbao: Virus.

Casanova, J. (coord.) (2002): Morir, matar, sobrevivir. Barcelona: Crítica.

C[astro] V[illacañas], A. (febrero 1943): "Primera novela de un universitario". En: Haz (4 época).

Cela, C. J. (1993): Memorias, entendimientos y voluntades. Barcelona: Plaza y Janés, $3^{\mathrm{a}}$ ed.

(2 junio 1989): "Datos para la historia", Desde el palomar de Hita (XIII). En: folletones de $E l$ Independiente, 1 y 16.

Cenarro, A. (1997): Cruzados y camisas azules. Zaragoza: Universidad.

Cervera, J. (2006): Madrid en guerra. La ciudad clandestina. Madrid: Alianza.

Chueca, R. (1983) El Fascismo en los comienzos del régimen de Franco. Madrid: CIS.

Claret, J. (2006): El atroz desmoche. Barcelona: Crítica.

Colectivo 36 (1976): Libro blanco sobre las cárceles franquistas. París: Ruedo Ibérico.

Domínguez, A. (2004): El verano que trajo un largo invierno. Cádiz: Quórum.

Eiroa, M. (1995): Viva Franco. Málaga: Aprisa.

25 "El camarada Camilo José Cela" no sólo ocupará más y más altos puestos en la jerarquía del fascismo de estado, por supuesto, sino que también y en estricta lógica política e ideológica escribirá y publicará como meritaje y "rigurosos" actos de servicio: panfletos de propaganda nacionalsindicalista -esto es, La familia de Pascual Duarte, etc.-, informes de normalización -esto es, Viaje a la Alcarria, etc.-, recusaciones de los traidores a la ortodoxia y exaltaciones del "inconformismo" fascista -esto es, La colmena, etc.-, etc. 
Espinosa, F. (2003): La columna de la muerte. Barcelona: Crítica.

(2005): La justicia de Queipo. Barcelona: Crítica.

(2006): Contra el olvido. Barcelona: Crítica.

Figueres, J. M. (ed.), (2004): Madrid en guerra. Crónica de la batalla de Madrid. Barcelona: Destino.

Fortes, J. A. (enero-junio 2006): "La miseria de los intelectuales". En: El fingidor, 27-28, 18-19.

García Serrano, R. (11 enero 1947): "Los chicos de San Camilo, motorizados" ("Desde Roma", diciembre 1946). En: Arriba.

García Viñó, M. (2006): El Pais: la cultura como negocio. Tafalla: Txalaparta.

Giménez Caballero, E. (abril 1943): "Lazarillo se ha levantado y anda otra vez por España". En: Lazarillo: $3-4$.

Gracia, J. (ed.), (2007): El valor de la disidencia. Epistolario inédito de Dionisio Ridruejo, 19331975. Barcelona: Planeta.

Hernández, F. (2003): Mujeres encarceladas. Madrid: Pons.

Iglesias, O. (16 febrero 2007): "La historia, en los juzgados". En: El País, 54.

Jerez, M. (1982): Élites políticas y centros de extracción en España (1938-1957). Madrid: CIS.

Malefakis, E. (2001): Reforma agraria y revolución campesina en la España del siglo XX. Madrid: Austral.

(1 diciembre 2006): "Memoria histórica. Lo que falta para terminar la guerra civil" En: El País Domingo.

Martín, E. (junio 1982): "Camilo José Cela, bardo del franquismo".En: Quimera, 20, 14-18.

Martín, I. (2002): La postguerra en Valladolid. Valladolid: Ámbito.

Martínez Cachero, J. M² (1973): La novela española entre 1936 y 1969. Historia de una aventura. Madrid: Castalia.

(julio-agosto 1978): "El septenio 1940-46 en la Bibliografía de Camilo José Cela". En: Cuadernos Hispanoamericanos, 337-338, 34-50.

Montero, M. (1993): Historia de la Asociación Católica Nacional de Propagandistas. La construcción del estado confesional, 1936-1945. Pamplona: Eunsa.

Moreno, F. (2001): La resistencia armada contra Franco. Barcelona: Crítica.

Morente, F.(1997): La escuela y el Estado Nuevo. Valladolid: Ámbito.

Morodo, R. (1985): Los origenes ideológicos del franquismo. Madrid: Alianza.

Negró, L. (2006): El diario El País y la cultura de las élites durante la Transición. Madrid: Foca.

Palomares, J. M ${ }^{\mathrm{a}}$. (2002): El primer franquismo en Valladolid. Valladolid: Universidad.

Parejo, J. A. (2004): La Falange en la Sierra Norte de Sevilla (1934-1956). Sevilla: Ateneo.

Pérez, T. y A. Fuentes, (1986): "De rebeldes a cruzados". En: Studia Historica, IV. 4, 235-266.

Primo de Rivera, J. A. (1954): "Discurso de la Fundación de Falange Española", Teatro de la

Comedia, 29 actubre 1933. En: Obras Completas (A. del Río, ed.), Madrid: D. N. Sección Femenina F. E. T. y J.O.N.S.

Reig Tapia, A. (1986): Ideología e historia. Madrid: Akal.

(1990): Violencia y terror. Madrid: Akal.

(2006): La cruzada de 1936. Madrid: Alianza.

Ridruejo, D. (noviembre 1940): "El poeta rescatado". En: Escorial, I, 1: 93-100.

Rivaya, B. (1998): Filosofia del derecho y primer franquismo (1937-1945). Madrid: CEPC.

Rodríguez Puértolas, J. (2007): Literatura fascista en España. Madrid: Akal, (2 $2^{a}$ ed.). 
Rodríguez Rivero, M. (28 noviembre 1998) "El segundo mercado del libro" En: El País Babelia: 3.

Southworth, H. R. (1963): El mito de la Cruzada de Franco. París: Ruedo Ibérico. (1967): Antifalange. París: Ruedo Ibérico.

(1999): "El gran camuflaje: Julián Gorkin, Burnett Bollonten y la guerra civil española". En: La Repúbiica asediada (P. Preston, ed.). Barcelona: Península: 265-310.

Umbral, F. (1993): Madrid 1940. Barcelona: Planeta.

Vilanova, F. (2005): La Barcelona franquista i l'Europa totalitaria (1939-1946). Barcelona:

Empúries.

Vinyes, R. (2002): Irredentas. Madrid: Temas de Hoy.

Viñas, Á. (2006): La soledad de la República. Barcelona: Crítica.

(2007): El escudo de la República. Barcelona: Crítica.

VV. AA. (1990): Justicia en guerra. Madrid: Ministerio de Cultura.

Zamora Vicente, A. y J. Cueto, (1995): Retrato de Camilo José Cela. Barcelona: Círculo de Lectores/Galaxia Gutenberg.

Z[unzunegui], J. A. de (enero 1943): "La familia de Pascual Duarte', por Camilo José Cela". En: Vértice, VI, 63. 


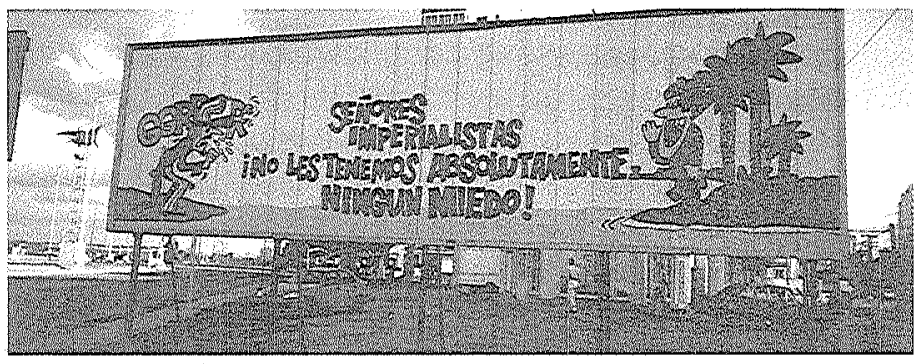




\section{LITERATURA HISPANOAMERICANA}

La labor crítica de Julio Rodríguez Puértolas en el campo de la literatura hispanoamericana tiene como claro referente la Cuba posterior a 1959. El acercamiento a una realidad convulsa como es la del continente americano se hace desde posturas ideológicas claramente delimitadas y muy relacionadas con las luchas de independencia de las diversas repúblicas americanas, luchas que, por supuesto, no terminan en 1898. En este sentido es esencial el estudio publicado en 1999 sobre las diversas perspectivas que provocó el llamado Desastre para poner de manifiesto una sensibilidad paralela a ambos lados del Atlántico ante el descubrimiento de un enemigo común, el nuevo imperio moderno que iba a ocupar el lugar dejado por España. La conciencia de esta nueva realidad, presente ya en la obra de José Martí, marca de forma clara el derrotero de unos estudios literarios interesados especialmente en las obras dedicadas a proponer un análisis que dé cuenta de la situación económica y política de América Latina. Esto explica la dedicación especial que ha merecido la obra de Alejo Carpentier, cuya «teoría de los contextos» resulta esencial como instrumento de indagación a la par que propone un nuevo camino para la novelística latinoamericana. Los estudios de Rodríguez Puértolas en este campo se centran en la llamada «literatura comprometida», es decir, aquella que asume la propuesta de Carpentier de ver en el escritor a un mero cronista de una realidad que necesita especialmente ser ubicada en el contexto universal. La trascendencia de la obra del escritor cubano explica que haya sido él el que ha recibido una atención casi exclusiva frente a otros grandes nombres de la literatura hispanoamericana. Rodríguez Puértolas se ha dedicado a la producción novelística que abrió el camino a la madurez de la literatura en el nuevo continente. La teoría de lo «real maravilloso» y todo lo que conlleva en cuanto a estilo, perspectiva sobre la realidad, etc., nos sitúa en la línea que llega hasta García Márquez, Carlos Fuentes o incluso Octavio Paz y Vargas Llosa en sus comienzos, autores a los que Rodríguez Puértolas no ha dedicado ningún estudio (del caso de García Márquez hablaremos después). Esta situación hace que destaque poderosamente el artículo sobre Jorge Luis Borges, autor al que conoció personalmente durante su estancia en Estados Unidos. Borges le sirve a Rodríguez Puértolas como contrapunto de la corriente literaria en Latinoamérica encabezada por Carpentier. Un escritor que afirma sentirse mucho más cómodo en la cultura anglosajona que en la hispana está también tomando partido por un acercamiento a la realidad que se aleja profundamente de la indagación en el ser latinoamericano. El artículo representa un intento de desmontar lugares comunes sobre el escritor consagrado tanto desde un punto de vista ideológico como estilístico, aspectos que Rodríguez Puértolas no separa en ningún momento. En cuanto a otros nombres, hemos querido incluir en esta sección las notas dedicadas a las relaciones entre Galdós y García Márquez o Cortázar, notas en las que se pone de manifiesto la influencia que el escritor español tuvo sobre la nueva narrativa hispanoamericana del siglo XX y su relación con una literatura que se alejaba del realismo tradicional tanto como la del propio Galdós. Los injustos ataques que le dedica Cortázar en su novela Rayuela son rebatidos precisamente por la renovación que supone Galdós para la literatura en español y que Rodríguez Puértolas pone en relación con la producción que se está llevando a cabo en la América hispana a partir de 1940. 
Pero como muy bien supo ver Rodríguez Puértolas, con Carpentier no se había llegado al final del camino y ahí está el estudio dedicado a Manuel Cofiño, escritor que, sin abandonar el compromiso con su realidad, supera la noción de realismo mágico y de real maravilloso.

La polifacética realidad latinoamericana explica la presencia en esta bibliografía de estudios dedicados a temas como los corridos y el bolero, expresión popular de una sensibilidad hispana, latina, que no se acaba en la literatura con mayúscula. Las relaciones de España y Cuba se concretan en esta bibliografía en la revista Orígenes que dio cabida a tantos exiliados republicanos.

1974: «Chicanos y corridos». En: Papeles de Son Armadans. Palma de Mallorca, 121-151.

1975: «Galdós y García Márquez». En: Galdós: burguesía y revolución. Madrid: Turner, 208212.

1975: «Galdós y Cortázar». En: Galdós: burguesía y revolución. Madrid: Turner, 212-218.

1978: «Manuel Cofiño o la superación de lo real maravilloso». En: Homenaje a Julio Caro Baroja. Madrid, 931-940.

1984: «España en Alejo Carpentier». En: Las relaciones literarias entre España e Iberoamérica. Actas XXIII Congreso Instituto Internacional de Literatura Iberoamericana. Madrid: ICI y UCM.

1987: «Alejo Carpentier, España y los españoles, 1928-1937». En: Las relaciones literarias entre España e Iberoamérica. Actas XXIII Congreso Instituto Internacional de Literatura Iberoamericana. Madrid, 587-594.

1987: «Borges: falacia ideológica y negación de la Historia». En: Literatura Hispano-Americana. Actas Quinto Curso de Verano Universidad del País Vasco. Bilbao, 91-120.

1988: «Significación de Alejo Carpentier». En: Anthropos. Serie Premios Cervantes (Alejo Carpentier). Barcelona, 81-102.

1989: «La narrativa de Manuel Cofiño».En: Acerca de Manuel Cofiño. La Habana: Letras Cubanas, 109-131.

1989: «La explosiva participación española en la revista Orígenes». En: Proposiciones, I.3.

1990: «El pueblo chicano en sus corridos». En: República de las Letras (número especial: 14921992. España-América: 500 años de Historia), 26, 165-174.

1995: «Orígenes «a la española», 1944-1956». En: Proposiciones, vol. I.3. La Habana, 14-25.

1996: «Sobre civilizaciones, barbaries y otros mitos. José Martí». En: La Ortiga. Revista trimestral de arte, literatura y pensamiento, vol. I.2. Santander, 11-19.

1998: Edición de La consagración de la primavera, de Alejo Carpentier. Madrid: Castalia.

1999: El Desastre en sus textos. La crisis del 98 vista por los escritores contemporáneos. Madrid: Akal.

2004: Estudio y edición de: Crónicas de España (1925-1937), de Alejo Carpentier. La Habana: Letras Cubanas.

2004:«El bolero: historia de un amor y de algo más». En: Actas Congreso Internacional Lyra Mínima Oral-III. Fundación Machado y Universidad de Sevilla, 511-527.

2005: «Consideraciones sobre Carpentier y la literatura española del siglo XX». En: Actas del Seminario Internacional Alejo Carpentier y España. Santiago de Compostela: Universidad de Santiago de Compostela. 